\title{
AVALIAÇÃO SENSORIAL DE SORVETE FORMULADO COM PRODUTO DE SORO ÁCIDO DE LEITE BOVINO ${ }^{1}$
}

\author{
Karla SILVA ${ }^{2, *}$, Helena Maria André BOLINI ${ }^{3}$
}

\begin{abstract}
RESUMO
O soro de leite bovino é um subproduto da fabricação do queijo ou da caseína, existente na forma ácida ou doce. Constituído basicamente de água, proteínas, lactose e minerais, quando concentrado, implica na obtenção de vários ingredientes protéicos de alta funcionalidade e valor nutricional. Entretanto, a concentração do soro tem sido realizada apenas ao soro doce, sendo o soro ácido, devido às suas características, geralmente tratado como resíduo. Neste contexto, este artigo apresenta os resultados obtidos com a introdução de produto de soro ácido de leite na formulação de sorvete, em sistema modelo, verificando a percepção dos provadores para diferentes percentuais de substituição do leite desnatado. As amostras de sorvete foram preparadas com composição de mistura: $2,5 \%$ de gordura látea, $18,3 \%$ de sacarose, $2,3 \%$ de gema de ovo em pó e 0,3\% de estabilizante-emulsificante e essência de baunilha. O sorvete padrão (P) foi formulado com 10,09\% de leite desnatado em pó. Quatro outras misturas foram preparadas com o produto de soro ácido em pó (SAP), substituindo o leite desnatado, em níveis 100, 80, 60 e $30 \%$. A avaliação do efeito provocado no sorvete, devido à substituição do leite desnatado por SAP, foi efetuada por ensaio sensorial direcionado à percepção do gosto doce. Não houve diferença estatisticamente significativa $(p \leq 0,5)$ entre as amostras quanto ao gosto doce avaliado. Houve boa aceitação dos provadores nos níveis de 60 e 30\% em substituição.

Palavras-chave: sorvete, soro ácido, tecnologia, sobremesa, sensorial.
\end{abstract}

\section{SUMMARY}

ICE-CREAM SENSORY EVALUATION FORMULATED WITH PRODUCT OF ACID BOVINE MILK SERUM. Whey, by-product of cheese or casein production, is classified in sweet or acid whey. Composed by water, proteins, lactose and minerals, when concentrated it produces proteins ingredients with high functionality and nutritional value. However, whey protein manufacturing has been applied only to sweet whey. Acid whey has been generally dumped down as dairy waste. This paper shows results obtained from acid whey product addition in ice cream formulation, in model system, ascertaining by sensory evaluation the panelists acceptance for five different milk substitutions levels. Ice cream samples were made with a mix composition of $2.5 \%$ milk fat, $18.3 \%$ sucrose, $2.3 \%$ egg yolk solids, $0.3 \%$ stabilizer-emulsifier and vanilla flavor. Standard ice cream (P) was formulated with $10.09 \%$ of dry skim milk. Other four mixture were repared with dry acid whey product (SAP) replacing dry skim milk in 100, 80, 60 e $30 \%$ levels. Evaluation of effect for using SAP, to total or partial replace of dry skim milk, was done by sweet taste sensory test. There was no statically significative difference $(\mathrm{p} \leq 0.5)$ between samples for sweet taste. There was good panelists acceptance for 60 and $30 \%$ substitutions levels.

Keywords: ice-cream, acid whey, technology, dessert, sensory.

\section{1 - INTRODUÇÃO}

O leite é composto de água, lactose, gordura, sais e proteína. As proteínas podem ser divididas em dois grandes grupos: as caseínas, insolúveis em $\mathrm{pH} 4,6$ e $20^{\circ} \mathrm{C}$, e as proteínas do soro [21]. Da separação do coágulo do leite integral, creme ou leite desnatado obtém-se o soro [31]. O soro contém aproximadamente $20 \%$ das proteínas solúveis do leite, quase todo o açúcar do leite (lactose) e cerca de $50 \%$ de todos os nutrientes consumidos normalmente no leite [15]. Distingue-se o soro doce (leite coagulado com renina em pH 6,6 [6]) do soro ácido (subproduto da coagulação ácida do leite [2]).

Formado por uma mistura de proteínas com numerosas e diversas propriedades funcionais (como emulsificação, aeração, formação de gel), o soro de leite bovino tem potencial conside-

\footnotetext{
${ }^{1}$ Recebido para publicação em 4/2/2005. Aceito para publicação em 23/1/2006 (001477)

${ }^{2}$ Departamento de Engenharia de Alimentos, Faculdade de Engenharia de Alimentos Universidade Estadual de Campinas (Unicamp)

E-mail:kasi@fea.unicamp.br

${ }^{3}$ Departamento de Alimentos e Nutrição, Faculdade de Engenharia de Alimentos. Unicamp

E-mail:hellini@fea.unicamp.br

*A quem a correspondência deve ser enviada
}

rável de utilizações [16], necessitando de processamento para tornar-se o ingrediente protéico adequado para uma utilização específica [13]. Países como Estados Unidos, Austrália, Canadá e Nova Zelândia e nações da União Européia processam este subproduto reconhecendo-o como ingrediente funcional e agregando valor à linha de produção da indústria látea. No Brasil, os dados sobre a disponibilidade do soro de leite são altamente imprecisos [2], mas boa parte do queijo é produzida por pequenas empresas que, evitando o custo do tratamento deste efluente e sem fiscalização efetiva das autoridades, optam pela utilização parcial deste subproduto como alimentação animal, descartando o excedente diretamente nos rios. Sendo uma das mais potentes de todas as águas residuais da indústria láctea [24], e tendo estimativa de produção mundial de 145 bilhões de kg por ano [29], a questão é transformar este subproduto de um problema em uma oportunidade nacional.

A aplicação de sólidos de soro de leite como substituinte do leite desnatado em sorvete é recomendada uma vez que, além do ganho biológico por conter as proteínas relacionadas com a prevenção do câncer de próstata [5], confere melhoria das propriedades funcionais (viscosidade, solubilidade, gelificação, emulsificação, formação de espuma, estabilidade) e reduz custos do produto final [4]. A legislação brasileira não faz referência quanto à aplicação de ingredientes protéicos de soro de leite em sorvete. 
Sob argumento de que a adição excessiva de soro de leite provocaria características indesejáveis, como arenosidade ou gostos residuais, o nível de substituição é limitado em certos países como Inglaterra e Estados Unidos [19].

Fabricantes norte-americanos de sorvete, que já utilizam produtos de soro em suas formulações comprovando a viabilidade do uso desse produto, têm solicitado o aumento do nível de $25 \%$ de substituição dos sólidos não gordurosos do leite (SNGL), por produtos de soro de leite [10]. Vários estudos demonstram que sorvetes formulados pela incorporação de diferentes ingredientes protéicos de soro de leite bovino, em lugar do leite em pó desnatado, têm características tão boas quanto o sorvete controle sem substituição [1, 7, 11, 14, 20, 22, 25, 26, 27, 28, 30]. CODER \& PARSONS [7], YOUNG et al. [30], PARSONS et al. [25], ADESSO \& KLEY [1] e LEE \& WHITE [18] registraram resultados positivos para sorvetes formulados com diferentes produtos de soro de leite bovino, em níveis superiores aos estabelecidos por lei. Entretanto, não existem trabalhos publicados sobre a aplicação, em sorvetes, do soro ácido de leite bovino.

O objetivo deste trabalho foi verificar a introdução de produto de soro ácido de leite na formulação de sorvete, em diferentes níveis de substituição do leite em pó desnatado, para verificação da percepção dos provadores sobre a diferença provocada no gosto doce das diferentes amostras.

\section{2 - MATERIAL E MÉTODOS}

\section{1 - Definição da metodologia de processamento dos sorvetes}

Neste trabalho, foi estabelecido que as análises seriam realizadas imediatamente após o processamento, uma vez que as alterações decorrentes do tempo de estocagem não foram avaliadas.

O processo foi desenvolvido em sistema modelo visando a minimização de custos e ressaltando que o objetivo final foi avaliar a aceitação sensorial dos diferentes produtos. As etapas seguidas estão especificadas no fluxograma da Figura 1.

\section{2 - Formulações das misturas}

A formulação padrão foi definida com base nos padrões federais regulamentados no Diário Oficial da União de 29 de abril de 1999, considerando formulações utilizadas em pesquisas científicas internacionais e formulações de produtos comerciais $[1,7,11,14,19,20,22,25,26,27$, $28,30]$. As demais misturas foram feitas por diferentes substituições do leite em pó desnatado por produto de soro ácido de leite em pó (SAP). Níveis de substituição do leite em pó desnatado por SAP escolhidos com extremos de substituição total e nenhuma. Os valores intermediários $(80,60,30 \%)$ foram indicados de forma a maximizar o percentual utilizado de soro verificando a aprovação dos provadores.

\subsection{1 - Ingredientes}

Foi utilizada fonte única para provimento de gordura látea, sacarose, gema de ovo, gordura vegetal, estabilizanteemulsificante e aroma em todas as formulações de sorvete. Definiram-se como ingredientes: açúcar granulado fino comercial, creme de leite pasteurizado (Nestlé Brasil Ltda.), gordura vegetal hidrogenada comercial, gema de ovo em pó, estabilizante-emulsificante (Selecta - Duas Rodas Industrial Brasil Ltda.) e aroma artificial de baunilha (Duas Rodas Industrial Brasil Ltda.). Na formulação do sorvete padrão utilizou-se leite em pó desnatado (Nestlé Brasil Ltda.), e as

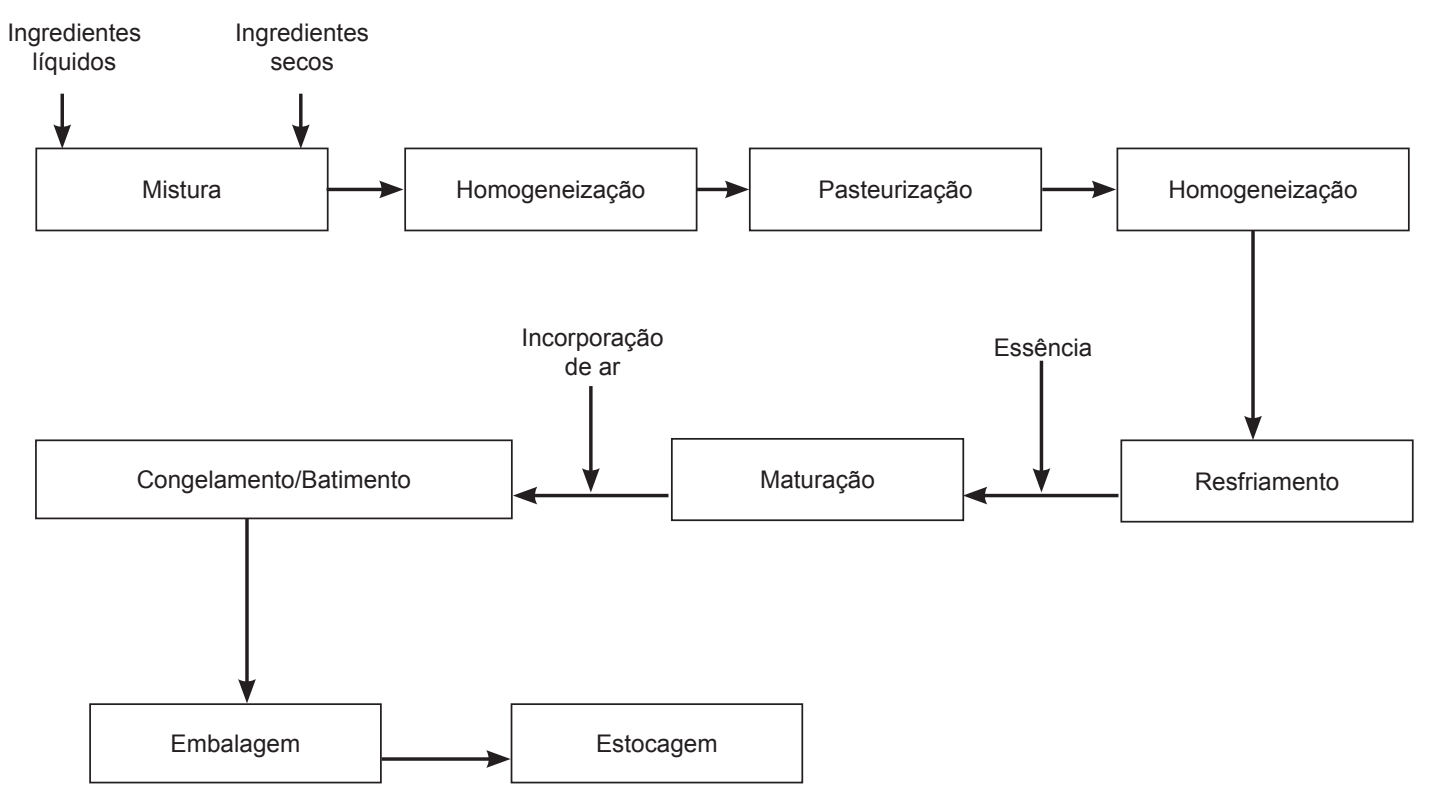

FIGURA 1 - Fluxograma de processamento dos sorvetes 
demais misturas foram feitas a partir de diferentes níveis de substituições de SAP.

- $\quad$ SAP - produto de soro ácido em pó: O soro fresco do queijo tipo quark ( $\mathrm{pH}$ 4,35 e 6,4\% sólidos totais), após ajuste de pH e concentração (pH 6,6 e 30\% de sólidos totais, Nestlé Brasil Ltda), foi fornecido líquido pela divisão de refrigerados da indústria Nestlé Brasil Ltda. Considerando que o tratamento por pressão não causa mudanças no gosto ou sabor de alimentos [12], procedeu-se secagem do soro por liofilização (liofilizador Edwards - super Modulyo) em pressão igual a $10^{-1}$ mbar e temperatura do condensador $-40^{\circ} \mathrm{C}$, aplicadas durante sete dias. O SAP foi devidamente embalado e armazenado a $4^{\circ} \mathrm{C}$ para utilização posterior.

- Gema de ovo em pó: o ovo inteiro fresco (12\% proteína, $28 \%$ sólidos totais e $10 \%$ gordura, segundo Jikkinti Yamaguishismo Agropecuária Ltda., Jaguariúna (SP), Brasil) foi quebrado separando-se clara e gema. A gema foi seca por liofilização (liofilizador Edwards - super Modulyo) a pressão $10^{-1}$ mbar e temperatura do condensador $-40^{\circ} \mathrm{C}$, aplicadas durante sete dias. O produto obtido foi embalado sob condições assépticas e conservado sob refrigeração $\left(4^{\circ} \mathrm{C}\right)$ até momento da utilização.

\subsection{2 - Caracterização dos ingredientes}

Foram realizadas análises de sólidos totais, gordura, proteína, lactose e cinzas, sempre em triplicatas, conforme especificado na seqüência.

- Sólidos totais: todos os ingredientes, exceto o aroma de baunilha e o composto estabilizante-emulsificante, foram submetidos a análise de sólidos totais utilizando metodologia oficial [3].

- Gordura: o teor de gordura nos produtos lácteos utilizados foi determinado pelo método de Mojonnier [19]. Para gordura vegetal hidrogenada, considerou-se a informação do fabricante de conteúdo sólido 100\% proveniente de material lipídico.
- Proteína: o percentual de proteína no leite, SAP e no creme de leite foi determinado pelo método de Kjeldahl [3].

- Carboidratos: para os produtos lácteos e SAP, considerando os carboidratos $100 \%$ em forma de lactose, utilizou-se a metodologia de determinação de açúcares não-redutores para os produtos lácteos [17]. Para o açúcar granulado, adotou-se a informação do fabricante de $100 \%$ dos sólidos totais vindos de carboidratos.

- Cinzas: o teor de cinzas foi determinado para todos os produtos lácteos por meio da metodologia oficial [3].

A gema de ovo em pó teve composição aproximada estimada por valores médios consultados na literatura [9]. Foi adotado teor de $100 \%$ em sólidos totais para o estabilizante-emulsificante, e desprezou-se a contribuição em sólidos totais devido ao aroma de baunilha.

\subsection{3 - Dosagem dos componentes das misturas}

O balanço de massa foi realizado desconsiderando a contribuição centesimal devido ao aroma de baunilha. Para efeitos de cálculos, ainda foi feita a aproximação de isenção de umidade do estabilizante-emulsificante. Foram preparadas cinco diferentes misturas:

- $\mathrm{A}_{100}$ - provimento dos sólidos não gordurosos do leite por $100 \%$ de soro;

- $\mathrm{A}_{80}$ - sólidos não gordurosos do leite representados por $80 \%$ de soro e $20 \%$ de leite desnatado;

- $\mathrm{A}_{60}$ - sólidos não gordurosos do leite representados por $60 \%$ de soro e $40 \%$ de leite desnatado;

- $\mathrm{A}_{30}-$ sólidos não gordurosos do leite representados por $30 \%$ de soro e $60 \%$ de leite desnatado;

- $\quad \mathrm{P}$ - provimento dos sólidos não gordurosos do leite por $100 \%$ de leite desnatado.

As quantidades dosadas dos ingredientes das misturas encontram-se especificadas na Tabela 1 .

TABELA 1 - Dosagem dos ingredientes das misturas com leite em pó e/ou SAP

\begin{tabular}{|c|c|c|c|c|c|}
\hline Ingrediente & \multicolumn{5}{|c|}{$\begin{array}{c}\text { Formulação } \\
\text { Massa }_{\text {base seca }}(\mathbf{g}) \text { - Sólidos totais (\%) }\end{array}$} \\
\hline Leite desnatado & $12,63-10,09$ & $0,00-0,00$ & $2,53-2,02$ & $5,05-4,03$ & $8,06-6,44$ \\
\hline SAP & $0,00-0,00$ & $13,82-10,09$ & $11,06-8,07$ & $8,29-6,06$ & $5-3,65$ \\
\hline Sacarose & $22,98-18,35$ & $22,98-18,35$ & $22,98-18,35$ & $22,98-18,35$ & $22,98-18,35$ \\
\hline Creme de leite & $4,65-3,71$ & $4,65-3,71$ & $4,65-3,71$ & $4,65-3,71$ & $4,65-4,71$ \\
\hline Gema de ovo & $2,93-2,34$ & $2,93-2,34$ & $2,93-2,34$ & $2,93-2,34$ & $2,93-2,34$ \\
\hline Estabiliz.-emul. & $0,4-0,32$ & $0,4-0,32$ & $0,4-0,32$ & $0,4-0,32$ & $0,4-0,32$ \\
\hline Água & $65-0,00$ & $64,34-0,00$ & $64,34-0,00$ & $64,51-0,00$ & $64,7-0,00$ \\
\hline TOTAL & $125,2-40,4$ & $125,2-40,4$ & $125,2-40,4$ & $125,2-40,4$ & $125,2-40,4$ \\
\hline
\end{tabular}




\section{3 - Controles do processo}

Durante todas as etapas houve acompanhamento sistemático da temperatura, fixando desvios máximos tolerados de $2^{\circ} \mathrm{C}$ para temperatura do produto (termômetro colocado no ponto central do recipiente contentor do produto). Conforme verificado em ensaios preliminares, os diferentes tempos de batimentos provocam variações na distribuição dos cristais de gelo do produto, assim, os tempos e condições de batimentos foram rigorosamente respeitados. As condições para trocas térmicas foram estabelecidas e mantidas para cada um dos processamentos.

\section{4 - Preparo dos produtos}

Os ingredientes secos, exceto o leite ou o SAP utilizado como substituinte do leite, foram adicionados a $10 \%$ da água $\left(75 \pm 2^{\circ} \mathrm{C}\right.$ ) e homogenizados. O leite (ou as diferentes combinações com SAP) foi acrescentado ao restante da água $\left(75 \pm 2^{\circ} \mathrm{C}\right)$ necessária à mistura e aquecido a $78 \pm 2^{\circ} \mathrm{C}$ imediatamente antes de sua adição aos demais ingredientes previamente homogenizados. Seguiram-se pasteurização, refrigeração imediata e adição do aroma de baunilha em taxa de $0,2 \mathrm{~mL} / \mathrm{L}$ sob agitação a $200 \mathrm{rpm}$. Foram feitas três bateladas homogeneizadas em uma única mistura. A mistura seguiu então para maturação com posterior congelamento em freezer a $-20 \pm 2^{\circ} \mathrm{C}$ por $8 \mathrm{~h}$. O sorvete, resfriado a uma temperatura aproximada de $-5^{\circ} \mathrm{C}$, foi aerado. O procedimento de congelamento por mais $5 \mathrm{~h}$ seguido de aeração durante 3 min foi repetido duas vezes, seguindo imediato armazenamento a $-20 \pm 2^{\circ} \mathrm{C}$ até amostragens para análise.

\section{5 - Especificações das etapas de processamento}

As condições de processamentos e equipamentos foram fixadas. Os processamentos foram feitos em sistema tipo batelada com aproveitamento de $50 \%$ da capacidade máxima de volume ( $1 \mathrm{Kg}$ ) dos contendores dos produtos. A temperatura ambiente permaneceu controlada em $25 \pm 5^{\circ} \mathrm{C}$, e as condições de aquecimento, agitação, mistura, resfriamento, aeração e congelamento foram sistematicamente mantidas no decorrer de todos os processamentos.

- Dosagem dos ingredientes - todos os ingredientes foram previamente pesados em balança semi-analítica;

- Mistura - água, a $75 \pm 2^{\circ} \mathrm{C}$, foi acrescida aos ingredientes secos então misturados por agitação mecânica (Marconi, modelo MA085), em velocidade de $200 \mathrm{rpm}$ por período de $10 \mathrm{~min}$;

- Homogeneização - efetuada por homogeneizador mecânico (Fisatom, modelo 713D), a 4.500 rpm durante $10 \mathrm{~min}$;

- Pasteurização - Aquecimento controlado em placa de aquecimento até a temperatura estabelecida $\left(78 \pm 2^{\circ} \mathrm{C}\right)$ por $30 \mathrm{~min}$ sob agitação a $200 \mathrm{rpm}$. Trocas térmicas com o meio ambiente foram minimizadas com uso de isolante;

- Resfriamento e Maturação - utilizada refrigeração à temperatura controlada de $4 \pm 2^{\circ} \mathrm{C}$. A maturação foi feita por $8 \pm 1 \mathrm{~h}$;

- Congelamento/Batimento - as condições para troca térmica foram fixadas padronizando-se o posicionamento das amostras dentro do equipamento, assim como o número de amostras por batelada de teste e o volume de produto. O congelamento seguiu a $-20 \pm 2^{\circ} \mathrm{C}$ durante $8 \mathrm{~h}$ com subseqüente incorporação de ar. Foi utilizado aerador mecânico (Walita R/3164/66) em velocidade baixa por $3 \mathrm{~min}$. O tempo e o número de batimentos, na etapa de congelamento, foram fixados, baseando-se em testes preliminares para verificação do máximo em overrun obtido.

\section{6 - Avaliação sensorial dos produtos}

O impacto provocado no sorvete devido a substituição do leite desnatado por SAP foi avaliado por ensaio sensorial. O alto teor de lactose do SAP poderia conferir gosto doce embora o conteúdo excessivo de minerais pudesse conferir gosto salgado ao produto final. Desta forma, a possibilidade de alterações no sabor foi conferida conduzindo os testes para verificação da percepção quanto ao gosto doce.

\subsection{1 - Descrição do teste}

- Teste aplicado: ordenação-doçura;

- Condições de aplicação do teste:

- Local: os testes foram aplicados no Laboratório de Sensorial do Departamento de Alimentos e Nutrição da Faculdade de Engenharia de Alimentos da Unicamp. As cabines, individuais, equipadas com cadeiras e mesas devidamente projetadas, iluminadas por luz branca, foram climatizadas a $20 \pm 2^{\circ} \mathrm{C}$;

- Objetivo: determinar se existe diferença significativa, quanto ao atributo gosto doce, entre amostras de sorvete com diferentes níveis de substituição do leite em pó desnatado por soro de leite ácido. Ter opinião do provador, em forma de comentários, sobre os produtos provados;

- Preparação das amostras: foram oferecidas as cinco diferentes amostras: $P, A_{100}, A_{80}, A_{60}, A_{30}$;

- Equipe de provadores: 15 pessoas, familiarizadas com o procedimento e o produto;

- Princípio do teste: cada provador recebeu as cinco amostras codificadas com algarismos aleatórios de três dígitos, em suporte térmico para conservação da temperatura da amostra (Figura 2). Foi solicitado que as amostras fossem provadas da esquerda para a 
direita e classificadas por ordem crescente de doçura, anotando a ordem na ficha fornecida (Figura 3);

- Procedimento: as amostras foram codificadas com algarismos aleatórios de três dígitos, posicionadas ao acaso em bandeja térmica e oferecidas simultaneamente aos provadores;

- os provadores não eram informados sobre as formulações ou objetivos da pesquisa;

- o provador poderia repetir o teste, neste caso, receberia uma nova série de amostras codificadas diferentemente.

- os provadores foram incentivados a escrever suas opiniões a respeito de cada um dos produtos, principalmente em caso de preferência ou rejeição de alguma amostra.

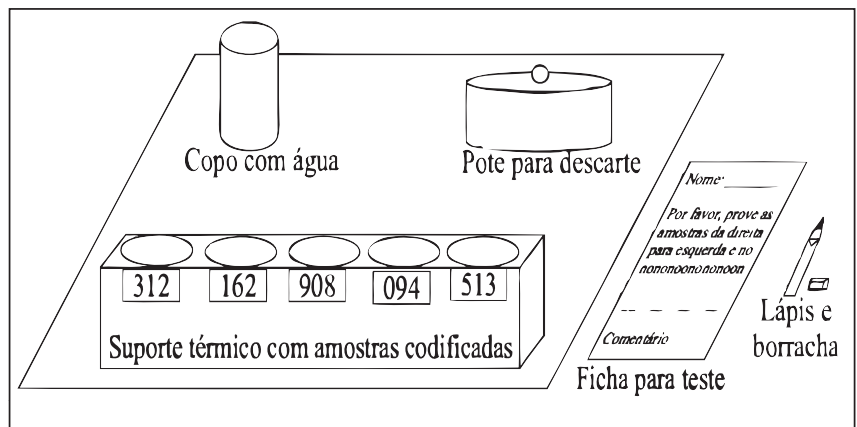

FIGURA 2 - Apresentação das amostras para teste sensorial

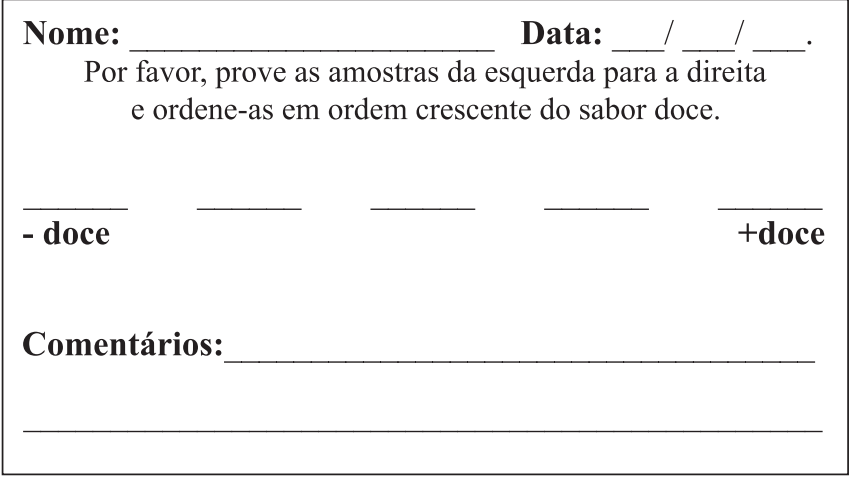

FIGURA 3 - Ficha para teste sensorial de ordenação-doçura
- Análise dos resultados: os resultados foram analisados usando a tabela de NEWELL E MAC FARLANE (1987)[23].

\section{3 - RESULTADOS E DISCUSSÃO}

\section{1 - Caracterização dos ingredientes}

A composição determinada dos ingredientes utilizados encontra-se listada na Tabela 2. Observou-se que o SAP apresenta menor teor protéico, teor em carboidratos mais elevado e alto teor em minerais (14\%) comparativamente ao leite em pó desnatado, em conformidade com o esperado e registrado por outros autores [6, 8, 16].

O percentual de proteínas no SAP é cerca de quatro vezes inferior ao do leite desnatado em pó desnatado. O SAP ainda contém duas vezes e meia mais gordura, quase o dobro em cinzas e pouco mais ( 1,25 vezes) em carboidratos (lactose), comparativamente ao leite em pó desnatado. O aumento do percentual de substituição do leite em pó desnatado por SAP acarreta, portanto, a diminuição de proteínas e o aumento do percentual de gordura, de cinzas e de lactose.

\section{2 - Avaliação sensorial dos produtos}

Os resultados do teste de ordenação-doçura encontramse listados na Tabela 3 e a ordem decrescente de doçura (mais doce para a menos doce) estabelecida foi:

$$
A_{60}{ }^{a}>A_{30}{ }^{a}>A_{100}{ }^{a}>A_{80}{ }^{a}>P^{a}
$$

TABELA 3 - Diferença entre totais de ordenação-doçura dos sorvetes formulados com leite em pó e/ou SAP

\begin{tabular}{lcccccc}
\hline \multirow{2}{*}{ Amostras } & Total & $\mathbf{A}_{100}$ & $\mathbf{A}_{80}$ & $\mathbf{A}_{60}$ & $\mathbf{A}_{30}$ & $\mathbf{P}$ \\
\cline { 2 - 7 } & & $\mathbf{4 4}$ & $\mathbf{4 2}$ & $\mathbf{4 8}$ & $\mathbf{4 7}$ & $\mathbf{2 9}$ \\
\hline $\mathrm{A}_{100}$ & 44 & - & $2^{\text {ns }}$ & $4^{\text {ns }}$ & $3^{\text {ns }}$ & $15^{\text {ns }}$ \\
$\mathrm{A}_{80}$ & 42 & - & - & $6^{\text {ns }}$ & $3^{\text {ns }}$ & $13^{\text {ns }}$ \\
$\mathrm{A}_{60}$ & 48 & - & - & - & $1^{\text {ns }}$ & $19^{\text {ns }}$ \\
$\mathrm{A}_{30}$ & 47 & - & - & - & - & $18^{\text {ns }}$ \\
\hline
\end{tabular}

TABELA 2 - Composição aproximada dos ingredientes utilizados nos sorvetes formulados com leite em pó e/ou SAP

\begin{tabular}{|c|c|c|c|c|c|}
\hline Ingrediente $^{a}$ & Sólidos Totais (\%) & $\begin{array}{c}\text { Gordura } \\
(\%)\end{array}$ & $\begin{array}{c}\text { Proteína bruta } \\
(\% \mathrm{~N} \times 6.25)\end{array}$ & Carboidrato (\%) & $\begin{array}{c}\text { Cinzas } \\
(\%)\end{array}$ \\
\hline Açúcarb & 99,91 & - & - & 99,91 & - \\
\hline Creme de leite & $33,67 \pm 0,03$ & $22,26 \pm 0,48$ & $2,21 \pm 0,06$ & 8,65 & $0,55 \pm 0,01$ \\
\hline Gordura vegetal $^{c}$ & 99,97 & 99,97 & - & - & - \\
\hline Gema de ovo ${ }^{d}$ & 97,71 & 61,14 & 31,97 & 1,2 & 3,4 \\
\hline Leite desnatado & $97,15 \pm 0,01$ & $0,63 \pm 0,63$ & $34,98 \pm 0,32$ & $53,52 \pm 0,46$ & $8,02 \pm 0,04$ \\
\hline
\end{tabular}

a Exceto estabilizante-emulsificante e aroma de baunilha. ${ }^{\mathrm{b}}$ Considerou-se $100 \%$ em forma de carboidrato. ${ }^{\mathrm{c}}$ Considerou-se $100 \%$ em forma de gordura. ${ }^{\mathrm{d}} \mathrm{Média}$ dos valores apresentados por Franco [9] 
ns - Não existe diferença significativa entre as amostras a $\mathrm{p} \leq 0,05$

A amostra $\mathrm{P}$ (sem substituição do leite em pó desnatado) e a amostra $A_{60}$ foram identificadas, respectivamente, como a menos doce e a mais doce, embora não tenha sido encontrada diferença estatisticamente significativa $(\mathrm{p} \leq 0,05)$ entre as amostras desta etapa quanto ao atributo doçura. Não houve correlação entre o nível de substituição com o SAP e a posição relativa de doçura. $\mathrm{O}$ atributo doçura não discriminou essas amostras provavelmente devido à confusão na percepção sensorial dos provadores provocada pela adição excessiva de SAP (mais rico em cinzas e lactose).

$\mathrm{O}$ alto teor em lactose confere gosto ligeiramente doce e o alto teor em minerais confere gosto ligeiramente salgado [19], assim, o sabor do produto final conteve gostos residuais diferentemente percebidos pelos indivíduos. Esta diferença na percepção individual foi registrada por alguns provadores em forma de comentários (Tabela 4). Esses comentários evidenciam as percepções quanto à substituição do leite desnatado por SAP. A amostra $\mathrm{A}_{100}$ foi evidenciada por 38,5 e $23 \%$ dos provadores como tendo sabor ruim e gosto salgado, respectivamente. A amostra $\mathrm{P}$ foi a que obteve o maior número de comentários como "amostra boa". A amostra com 100\% de SAP substituindo os sólidos não gordurosos do leite $\left(\mathrm{A}_{100}\right)$ foi a menos aceita (identificada como ruim por $35 \%$ dos provadores) e possuidora de gosto residual.

Reforçando a hipótese levantada sobre confusão sensorial provocada pelo conteúdo excessivo em SAP, 3 provadores identificaram a amostra contendo $100 \%$ de $\operatorname{SAP}\left(\mathrm{A}_{100}\right)$ como "muito doce", enquanto que um provador evidenciou a mesma amostra como "salgada". Houve aprovação dos produtos com substituições de SAP inferiores a 100\%: sete provadores (47\%) ressaltaram o gosto pelos produtos de substituições 80,60 ou $30 \%$. A amostra $A_{80}$ obteve tantos comentários identificando-a como "amostra boa" quanto a amostra $\mathrm{P}$ e excedendo a pontuação das amostras $\mathrm{A}_{60} \mathrm{e}$ $A_{30}$. Entretanto, recebeu um indicativo da percepção do provador quanto ao gosto residual. As amostras $\mathrm{A}_{60}$ e $\mathrm{A}_{30}$ obtiveram comentários similares entre si.

TABELA 4 - Observações de provadores, no teste de ordenaçãodoçura, para sorvetes com leite em pó e/ou SAP

\begin{tabular}{lccccc}
\hline Amostra & \multicolumn{5}{c}{ Contagem dos comentários } \\
\cline { 2 - 6 } & $\begin{array}{c}\text { Sabor } \\
\text { ruim }\end{array}$ & $\begin{array}{c}\text { Sabor } \\
\text { bom }\end{array}$ & $\begin{array}{c}\text { Gosto } \\
\text { residual }\end{array}$ & $\begin{array}{c}\text { Gosto } \\
\text { salgado }\end{array}$ & $\begin{array}{c}\text { Gosto } \\
\text { muito } \\
\text { doce }\end{array}$ \\
\hline $\mathrm{A}_{100}$ & 5 & 1 & 1 & 1 & 3 \\
$\mathrm{~A}_{80}$ & 1 & 3 & 1 & 1 & - \\
$\mathrm{A}_{60}$ & 1 & 2 & - & - & - \\
$\mathrm{A}_{30}$ & 1 & 2 & - & - & - \\
$\mathrm{P}$ & 1 & 3 & - & - & - \\
\hline
\end{tabular}

\section{4 - CONCLUSÕES}

Quanto ao teste de ordenação-doçura, embora a amostra $\mathrm{P}$ e a amostra $\mathrm{A}_{60}$ tenham apresentado, nesta ordem, o gosto menos doce e o mais doce, não diferiram significativamente $(\mathrm{p} \leq 0,05)$ das demais amostras, com nível de $5 \%$ em significância, quanto ao atributo doçura. A ordenação apresentada não demonstrou correlação entre o percentual de substituição e o atributo intensidade de doçura sugerindo que o conteúdo excessivo em lactose e minerais, do SAP comparativamente ao leite em pó desnatado, confundiu a percepção sensorial do gosto doce avaliado.

As amostras $A_{60}$ e $A_{30}$ obtiveram comentários similares entre si e igualmente positivos com relação a gostos notificados. Considerando, entretanto, a possibilidade de cristalização indesejável da lactose, quando em concentração excessiva, em sorvetes durante o período de armazenamento, e não tendo sido estudado tal aspecto na presente pesquisa, concluiu-se que o nível de substituição de $30 \%$ de leite desnatado por SAP, embora detectável pelos provadores quando comparado à ausência de substituintes, é mais conveniente. Assim, a formulação $\mathrm{A}_{30}$ foi a escolhida como preferencial para continuação da segunda etapa do presente trabalho.

\section{5 - REFERÊNCIAS BIBLIOGRÁFICAS}

[1] ADDESSO, K.M. e KLEY, K.H. Development of an acceptable ice cream possessing a reduced sodium content. Journal of Food Science, v. 51, n. 6, p. 1.467-1.470, 1986.

[2] ANTUNES, A.J. Funcionalidade de proteínas do soro de leite bovino, $1^{\mathrm{a}}$ ed., Editora Manole Ltda., 2003.

[3] Association of Official methods of analysis. $27^{\text {th }}$ ed., Washington DC, Worwitz, 6ª ed., 1996.

[4] BERGER, K.G. Ice cream. In: LARSSON, K. e FRIBERG, S. Food emulsions. New York, Marcel Dekker Inc., p. 413-489, 1997.

[5] BOMSER, J.; KENT, K. e HARPER, J. Effect of whey protein isolate on intracellular glutathione and oxidantinduced cell death in human prostate epithelial cells. Toxicol In Vitro, v. 17, n. 1, p. 27-33, 2003.

[6] CAYOT, P.; LORIENT, D. Structure-function relationships of whey proteins. In: DAMODARAN, S.; PARAF, A. Food proteins and their applications. New York, Marcel Dekker Inc., p. 225-255. 1997.

[7] CODER, D. e PARSONS, J.G. The effects of processes wheys and caseinate on composition and consumer acceptance of ice cream. Journal of Dairy Science, v. 62, Suppl. 1, p. 35-35, 1979.

[8] EVANS, E.W. Uses of milk proteins in formulated foods. In: HUDSON, B. J. F. Developments in food proteins. New York, Elsevier, p. 131-163, 1982.

[9] FRANCO, G. Composição química dos alimentos, Editora Atheneu, 9ª ed. p. 130, 1987.

[10] GALE GROUP. Ice-cream firms want to use more whey. The Food Institute Report. Washington, 2003. Disponível em: http://www.foodinstitute.com/c25/addtocarl.cfm > Acesso em: 23 jun. 2003.

[11] GUY, E.J. Partial replacement of nonfat milk solids and cane sugar in ice cream with lactose hydrolysed sweet whey solids. Journal of Food Science, Chicago, v. 45, n. 1, p. 129-133, 1980.

[12] HEREMANS, K.; CAMP, J.V. e HUYGHEBAERT, A. High-pressure effects on proteins In: DAMODARAN, S. e PARAF, A. Food proteins and their applications, New York, Marcel Dekker Inc., p. 473-502, 1997. 
[13] HUFFMAN, L.M. Procesing whey protein for use as a food ingredient. Food Techology, v. 50, n. 2, p. 49-52, 1996.

[14] HUSE, P.A.; TOWLER, C. e HARPER, W.J. Substitution of nonfat milk solids in ice cream with whey protein concentrate and hydrolyzed lactos. New Zealand Journal of Dairy Science and Technology, v. 19, n. 3, p. 255-261, 1984.

[15] JELEN, P. Industrial whey processing technology: An overview. Journal of Agriculture and Food Chemistry, v. 27, n. 4, p. 658-661, 1979.

[16] KINSELLA, J.E. Milk proteins: physicochemical and functional properties. CRC critical reviews in food science and nutrition, v. 21, n. 3, p. 197-262, 1984.

[17] LANARA. Métodos analíticos oficiais para controle de produtos de origem animal e seus ingredientes. Ministério da Agricultura, Secretaria Nacional de Defesa Agropecuária, Laboratório Nacional de Referência Animal. Brasília, 1981.

[18] LEE, F.Y. e WHITE, C.H. Effect of ultrafiltration retentates and whey protein concentrates on ice cream quality during storage. Journal of Dairy Science, v. 74, n. 4, p. 1.171-1.180, 1991.

[19] MARSHALL, R.T.; ARBUCKLE, W.S. Ice cream. International Thomson Publishing, $5^{\text {th }}$ ed., 349 p, 1996.

[20] MARTINEZ, S.B. e SPECHMAN, R.A. $\beta$-galactosidase treatment of frozen dairy product mixes containing whey. Journal of Dairy Science, v. 71, n. 4, p. 893-900, 1988.

[21] MAUBOIS, J.L.; OLLIVER, G. Extraction of milk protein In: DAMODARAN, S. e PARAF, A. Food proteins and their applications., New York, Marcel Dekker Inc., p.1.579-1.595, 1997.

[22] NAIDU, P.G.; RAO, T.J.; ALI, M.P.; SASTRI, P.M. Effect of utilization of whey in ice cream. Indian Journal of Dairy Science, v. 39, n. 1, p. 94-94, 1986.

[23] NEWELL, G.J.; MAC FARLANE, J.D. Expanded tables for multiple comparison procedures in the analysis of ranked data. Journal of Food Science, v. 52, n. 6, p. $1.721,1987$.
[24] ORCHARD, R.L. Wastes and effluent requirements of the dairy industry. American Dairy Review, v. 45, n. 5, p. 45-57, 1972.

[25] PARSONS, J.G.; DYBING, S.T.; CODER, D.S. Acceptability of ice cream made with processed wheys and sodium caseinate. Journal of Dairy Science, v. 68, n. 11, p. 2.880-2.885, 1985.

[26] REDDY, V.P.; RAMGAMADHAM, M.; REDDY, C.R.; KARNANI, B.T. Studies on the value of channa whey solids in the preparation of ice-cream in partial replacement of MSNF of mix. The Indian Journal of Dairy Science, v. 40, n. 1, p. 128-131, 1997.

[27] RUGER, P.R.; BAER, R.J.; KASPERSON, K.M. Effect of double homogenization and whey protein concentrate on the texture of ice cream. Journal of Dairy Science, v. 85, n. 7, p. 1.684-1.692, 2002.

[28] THOMPSON, L.U.; RENIERS, D.J.; BAKER, L.M. e SIU, M. Succinylated whey protein concentrates in ice cream and instant puddings, Journal of Dairy Science, v. 66, n. 8, p. 1.630-1.637, 1983.

[29] VOORBERGEN, M.; ZWANENBERG, A. Whey-ing up the future. Dairy Industries International, v. 67, n. 1, p. 25-28, 2002.

[30] YOUNG, C.K.; STULL, J.W.; TAYLOR, R.R.; ANGUS, R.C. e DANIEL, T.C. Acceptability of frozen desserts made with neutralized, hydrolyzed, fluid cottage cheese whey. Journal of Food Science, v. 45, n. 4, p. 805-809, 1980.

[31] ZALL, R.R. Trends in whey fractionation and utilization, a global perspective. Journal of Dairy Science, v. 67, n. 11 , p. 2.621-2.629, 1984.

\section{6 - AGRADECIMENTOS}

Ao Conselho Nacional de Pesquisa e Desenvolvimento Científico (CNPq) e à Fundação de Apoio ao Ensino de Pesquisa (Faep) pelo financiamento de pesquisa de mestrado. 